\title{
Tachycardia-induced cardiomyopathy
}

\author{
Bruno Tsutomu Nakatani, Marcos Ferreira Minicucci, Katashi Okoshi, Marina Politi Okoshi \\ Department of Internal Medicine, Botucatu Medical School, Sao Paulo State University, UNESP, Botucatu, Sao Paulo, Brazil \\ Correspondence to Dr Marina P Okoshi, mpoliti@fmb.unesp.br
}

\section{Summary}

Tachycardia-induced cardiomyopathy (TIC) is an important cause of heart failure as it is potentially reversible after ventricular rate control. A 66-year-old hypertensive woman presented with a 15-day history of tachycardia, dyspnoea and oedema. ECG revealed atrial fibrillation with ventricular frequency of 130 beats per minute (bpm). Echocardiogram showed dilated left ventricle (LV) with 0.39 ejection fraction. Angiography revealed non-obstructed coronary arteries. Heart rate and cardiac failure were controlled with amiodarone, digoxine, captopril, metoprolol and furosemide. During follow-up, despite drug dose optimisation, the patient kept complaining of tachycardia and dyspnoea with a ventricular rate between 108 and $120 \mathrm{bpm}$. Medical staff suspected she was not taking her medicines properly. Two months later, the patient was asymptomatic and had converted to sinus rhythm (heart rate of $76 \mathrm{bpm})$. Echocardiogram showed normal LV size and function. Patient's diagnosis was TIC. Although rare, TIC should be considered in all cases of systolic dysfunction associated with tachyarrhythmia.

\section{BACKGROUND}

Heart failure is a major healthcare problem due to its high prevalence and the severity of clinical manifestations. Leading causes of heart failure include coronary artery disease, arterial hypertension and cardiomyopathies. Although in many cases it is obscure, the aetiology of cardiac failure has considerable prognostic implications.

Tachycardiomyopathy or tachycardia-induced cardiomyopathy (TIC) is an important cause of heart failure as it is potentially reversible after appropriate heart rate control. TIC is characterised by left ventricular dilation and systolic dysfunction with subsequent heart failure resulting from sustained or highly frequent arrhythmias with rapid ventricular rate. Both supraventricular and ventricular arrhythmias can induce cardiomyopathy. ${ }^{1}$ Atrial fibrillation, the most prevalent sustained cardiac rhythm disorder, ${ }^{2}$ is considered the most common cause of TIC. ${ }^{3}$ We report the case of a hypertensive patient with highfrequency atrial fibrillation-induced cardiomyopathy.

\section{CASE PRESENTATION}

A 66-year-old woman was hospitalised with tachycardia and progressive dyspnoea and lower-limb oedema over 15 days. She had a 10-year history of irregularly treated arterial hypertension. Physical examination revealed heart rate of 130 beats per minute (bpm), arterial blood pressure of $140 \times 90 \mathrm{~mm} \mathrm{Hg}$, crackles in lower lung fields and bilateral lower-extremity oedema. On precordial examination, there were no murmurs or gallop sounds. ECG showed atrial fibrillation with ventricular rate of $130 \mathrm{bpm}$, left ventricle (LV) hypertrophy and non-specific ST-T wave changes (figure 1). Transthoracic echocardiogram revealed moderately enlarged atria (left atrium diameter $53 \mathrm{~mm}$, normal range $27-38 \mathrm{~mm}$; left atrium/aorta diameter ratio 1.56), dilated LV (LV end-diastolic diameter $58 \mathrm{~mm}$, normal range 39-53 $\mathrm{mm}$; LV end-systolic diameter $47 \mathrm{~mm}$ ) with an ejection fraction of 0.39 (Teichholz method, normal range $\geq 0.55$ ) and diffuse LV hypokinesis. Coronary angiography showed non-obstructed coronary

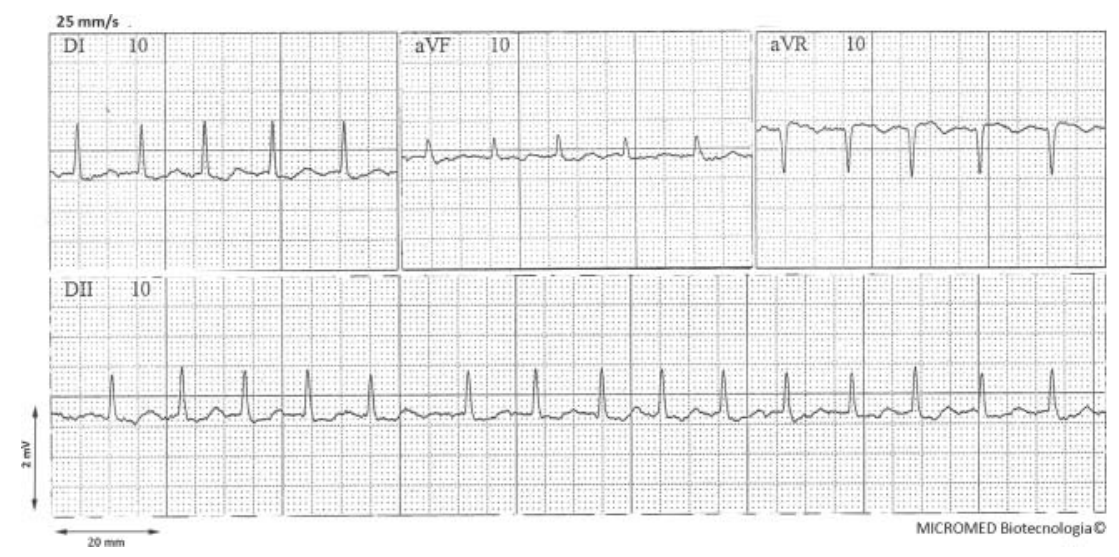

Figure 1 Resting ECG showing atrial fibrillation with a ventricular rate of approximately $130 \mathrm{bpm}$. 


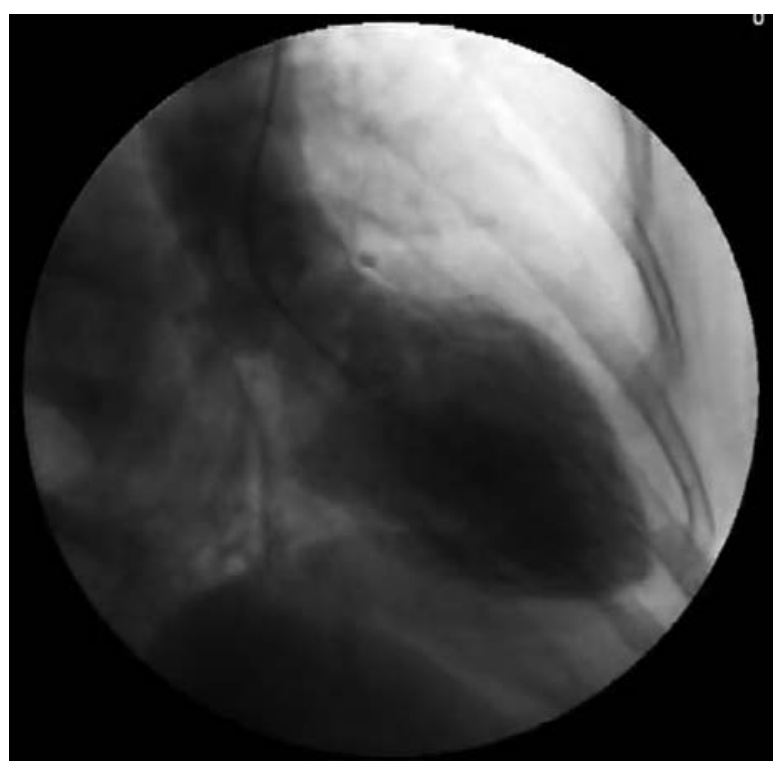

Video 1 Left ventriculography showing severe diffuse hypokinesis.

arteries, increased LV end-diastolic and systolic volumes, and severe diffuse hypokinesis with an ejection fraction of 0.30 (video 1).

Atrial fibrillation was considered to be permanent. Heart rate and cardiac failure were controlled with amiodarone, digoxine, captopril, metoprolol and furosemide. She was discharged with a ventricular rate of $76 \mathrm{bpm}$. As the patient had three risk factors for systemic embolisation (age, heart failure and hypertension), oral anticoagulation with warfarin was proposed. However, as she reported financial issues to attend medical appointments regularly, platelet antiaggregation with aspirin was initiated.

\section{INVESTIGATIONS}

Complementary assessment of heart failure patients with unknown tachycardia aetiology should include ECG to evaluate cardiac rhythm and myocardial ischaemia, and echocardiogram to determine left ventricular structure and functional characteristics, and exclude valvular and pericardial abnormalities. Coronary angiography is necessary if doubt remains regarding potential ischaemic aetiology of left ventricular dysfunction. Cardiac magnetic resonance can shed light on cardiomyopathy aetiology, and myocardial biopsy can be indicated in selected cases. ${ }^{4}$

\section{DIFFERENTIAL DIAGNOSIS}

All causes of dilated cardiomyopathy should be considered as differential diagnosis. Inherited disease should be suspected when there is a family history of premature cardiac death, conduction system disease or skeletal myopathy. Examples of non-familial causes of dilated cardiomyopathy include autoimmune disease, nutritional deficiencies, endocrine dysfunction, alcohol abuse, administration of cardiotoxic drugs, tachycardiomyopathy, and cardiac infection and inflammation. Valvular disease can be easily recognised by physical examination and echocardiogram.

\section{TREATMENT}

Treatment goals for patients with systolic heart failure are to relieve symptoms, prevent hospitalisation and improve survival. Recommendations for functional class III patients include an ACE inhibitor or angiotensin receptor blocker, a $\beta$-blocker and an aldosterone receptor antagonist, which are fundamentally important in modifying the course of systolic heart failure. Diuretics are often used to relieve congestive symptoms. Atrial fibrillation management is aimed at reducing symptoms and preventing systemic thromboembolism. Randomised trials comparing outcomes of rhythm versus rate control have found no differences in morbidity or mortality between approaches. Rate control therapy commonly includes $\beta$-blockers, nondihydropyridine calcium channel antagonists and/or digitalis. The combination of $\beta$-blocker and digitalis has beneficial effects for patients with atrial fibrillation and heart failure. Amiodarone can be used in patients with refractory rate control. Drugs frequently used to control cardiac rhythm are amiodarone and $\beta$-blockers such as sotalol, due to its ability to inhibit potassium channels. The decision to control rate or rhythm should be individually tailored. ${ }^{2}$

\section{OUTCOME AND FOLLOW-UP}

During her follow-up, despite drug dose optimisation, she kept complaining of tachycardia and dyspnoea on moderate exertion and presenting a ventricular rate between 108 and $120 \mathrm{bpm}$. Medical staff suspected she was not taking her medicines properly. Two months after initial evaluation, the patient was asymptomatic and had converted to sinus rhythm with a heart rate of $76 \mathrm{bpm}$. One day later, she had an acute ischaemic stroke in the right parietal and right frontal lobe, resulting in reduced left upper-limb strength. After the stroke, she agreed to receive anticoagulation with warfarin.

Echocardiograms performed 3 and 10 months after her initial evaluation revealed normal LV size (LV end-diastolic diameter $45 \mathrm{~mm}$ ) and function with an ejection fraction of 0.76 . LV mass/body surface area was $84 \mathrm{~g} / \mathrm{mm}^{2}$, LV posterior wall thickness $10 \mathrm{~mm}$, and relative wall thickness 0.44 ; left atrium was slightly enlarged; and diastolic function mildly impaired. Due to systolic function normalisation after reversion to sinus rhythm, her diagnosis was TIC.

\section{DISCUSSION}

The prevalence of TIC is unclear as it has only been reported in small retrospective series ${ }^{3}{ }^{5-7}$ or case studies. ${ }^{4}$ 8-11 This fact probably reflects the difficulty in differentiating TIC from dilated cardiomyopathy during acute heart failure. Generally TIC is retrospectively diagnosed when the impaired wall motion improves after control of the causal arrhythmia. ${ }^{3}$ The only difference between TIC and dilated cardiomyopathy patients in small studies ${ }^{3}{ }^{5}$ was that LV end-diastolic diameter was smaller in TIC patients. As TIC is considered a relatively acute process, short evolution could limit LV enlargement. ${ }^{4}$ In fact, Watanabe et $a l^{6}$ observed that mean time between the occurrence of tachyarrhythmias and heart failure development was $26.0 \pm 34.3$ days. There was no difference in serum concentrations of heart failure marker 
B-type natriuretic peptide between TIC and dilated cardiomyopathy patients. ${ }^{3}$

Despite difficulty in diagnosis, TIC is a known disease with well-established pathophysiological mechanisms described mostly in experimental studies. ${ }^{1}{ }^{12}$ During sustained rapid ventricular rate, heart failure can be caused by two main mechanisms, inadequate diastolic filling and tachycardia-induced systolic dysfunction. ${ }^{3}$ A number of cardiac changes can be involved in systolic dysfunction including myocyte and sarcomere loss, myofibril misalignment, extracellular matrix remodelling, calcium handling and adrenergic responsiveness abnormalities, oxidative stress, depletion of myocardial energy stores and myocardial ischaemia. ${ }^{1} 412$ Although less frequent, ventricular arrhythmias can cause TIC being associated to a more marked deterioration in left ventricular function than supraventricular tachyarrhythmias. ${ }^{13}$ In humans, TIC has been reported together with frequent isolated premature ventricular complexes, ${ }^{14}$ idiopathic left ventricular tachycardia $^{15}$ and repetitive monomorphic right ventricular outflow tract tachycardia. ${ }^{16-18}$ Tachycardia is not exclusively the only identifiable cause of myocardial dysfunction, it can also impair cardiac function in patients with structural heart disease. ${ }^{4}$ TIC is considered potentially reversible as symptoms often disappear and LV ejection fraction normalises after ventricular rate control. Improvement is fast in the first few weeks continuing slowly for up to 6 months. ${ }^{8}$ The absence of LV ejection fraction recovery does not discard TIC but may represent an advanced irreversible stage of the disease. ${ }^{10}$ The longterm prognosis has yet to be determined. In a small series, Nerheim $e t$ al $^{7}$ stated that TIC may have a long-term risk for sudden death.

In our case, the findings of low ejection fraction and dilated LV were compatible with dilated cardiomyopathy at an early phase or acute myocarditis. TIC diagnose was raised retrospectively, after reversion to sinus rhythm and systolic function normalisation. We cannot, however, discard the possibility that the patient had dilated cardiomyopathy and responded to heart failure treatment and rhythm control very well. Diastolic dysfunction was probably caused by aging and LV concentric remodelling, characterised by a combination of increased relative wall thickness and normal LV mass. Finally, we would like to stress the importance of prescribing anticoagulation to patients with atrial fibrillation and $\mathrm{CHA}_{2} \mathrm{DS}_{2}$-VASc score $\geq 1$.

\section{CONCLUSION}

Although rarely observed in a clinical setting, TIC is an important heart failure aetiology as it is potentially curable after heart rate control. This case reinforces the argument that it should be considered in all patients diagnosed with systolic dysfunction after or concomitantly to high-frequency atrial fibrillation or chronic tachyarrhythmia.

\section{Learning points}

- Tachycardia-induced cardiomyopathy (TIC) is usually associated with supraventricular tachycardia, particularly atrial fibrillation with rapid ventricular rate.

- Heart failure-related TIC is potentially reversible with proper control of ventricular rate.

- TIC can also impair cardiac function in patients with structural heart disease.

- Although rare, it should be considered in all cases of systolic dysfunction associated with tachyarrhythmias.

\section{Competing interests None.}

Patient consent Obtained.

\section{REFERENCES}

1. Umana E, Solares CA, Alpert MA. Tachycardia-induced cardiomyopathy. Am $J$ Med 2003;114:51-5.

2. Lip GY, Tse HF, Lane DA. Atrial fibrillation. Lancet 2012;379:648-61.

3. Fujino T, Yamashita T, Suzuki S, et al. Characteristics of congestive heart failure accompanied by atrial fibrillation with special reference to tachycardia-induced cardiomyopathy. Circ J 2007;71:936-40.

4. Lishmanov A, Chockalingam P, Senthilkumar A, et al. Tachycardia-induced cardiomyopathy: evaluation and therapeutic options. Congest Heart Fail 2010;16:122-6

5. Jeong YH, Choi KJ, Song JM, et al. Diagnostic approach and treatment strategy in tachycardia-induced cardiomyopathy. Clin Cardiol 2008:31:172-8.

6. Watanabe H, Okamura K, Chinushi M, et al. Clinical characteristics, treatment, and outcome of tachycardia induced cardiomyopathy. Int Heart $\mathrm{J}$ 2008;49:39-47.

7. Nerheim P, Birger-Botkin S, Piracha L, et al. Heart failure and sudden death in patients with tachycardia-induced cardiomyopathy and recurrent tachycardia. Circulation 2004;110:247-52.

8. Patel JJ, Whittaker CT. Tachycardia-induced heart failure. Perm J 2007:11:50-2.

9. Peake ST, Mehta PA, Dubrey SW. Atrial fibrillation-related cardiomyopathy: a case report. J Med Case Rep 2007:1:111.

10. Steinhoff JP, Sheahan RG. Tachycardia-induced cardiomyopathy: atrial fibrillation and congestive heart failure. Am J Med Sci 2005;329:25-8.

11. Walker NL, Cobbe SM, Birnie DH. Tachycardiomyopathy: a diagnosis not to be missed. Heart 2004;90:e7.

12. Shinbane JS, Wood MA, Jensen DN, et al. Tachycardia-induced cardiomyopathy: a review of animal models and clinical studies. J Am Coll Cardiol 1997;29:709-15

13. Zupan I, Rakovec P, Budihna N, et al. Tachycardia induced cardiomyopathy in dogs; relation between chronic supraventricular and chronic ventricular tachycardia. Int J Cardiol 1996;56:75-81.

14. Chugh SS, Shen WK, Luria DM, et al. First evidence of premature ventricular complex-induced cardiomyopathy: a potentially reversible cause of heart failure. J Cardiovasc Electrophysiol 2000;11:328-9.

15. Singh B, Kaul U, Talwar KK, et al. Reversibility of 'tachycardia induced cardiomyopathy' following the cure of idiopathic left ventricular tachycardia using radiofrequency energy. Pacing Clin Electrophysiol 1996;19:1391-2

16. Kim YH, Goldberger J, Kadish A. Treatment of ventricular tachycardia-induced cardiomyopathy by transcatheter radiofrequency ablation. Heart 1996; 76:550-2

17. Grimm W, Menz V, Hoffmann J, et al. Reversal of tachycardia induced cardiomyopathy following ablation of repetitive monomorphic right ventricular outflow tract tachycardia. Pacing Clin Electrophysiol 2001;24:166-71.

18. Jaggarao NS, Nanda AS, Daubert JP. Ventricular tachycardia induced cardiomyopathy: improvement with radiofrequency ablation. Pacing Clin Electrophysiol 1996:19(4 Pt 1):505-8. 


\section{BMJ Case Reports}

This pdf has been created automatically from the final edited text and images.

Copyright 2012 BMJ Publishing Group. All rights reserved. For permission to reuse any of this content visit http://group.bmj.com/group/rights-licensing/permissions.

BMJ Case Report Fellows may re-use this article for personal use and teaching without any further permission.

Please cite this article as follows (you will need to access the article online to obtain the date of publication).

Nakatani BT, Minicucci MF, Okoshi K, Politi Okoshi M. Tachycardia-induced cardiomyopathy. BMJ Case Reports 2012;10.1136/bcr-2012-006587, Published XXX

Become a Fellow of BMJ Case Reports today and you can:

- Submit as many cases as you like

- Enjoy fast sympathetic peer review and rapid publication of accepted articles

- Access all the published articles

- Re-use any of the published material for personal use and teaching without further permission

For information on Institutional Fellowships contact consortiasales@bmjgroup.com

Visit casereports.bmj.com for more articles like this and to become a Fellow 